\title{
As marcas da história na guerra civil síria
}

\author{
Muna Omran ${ }^{*}$
}

Hall, Clement M. The history of Syria: 1900-2012. Boston: Charles River Editors, 2013.

Escrito por M. Clement Hall, publicado em 2013, The history of Syria: 1900-2012 pretende ser uma leitura instigante por sugerir uma análise dos elementos constitutivos da história da Síria e por indicar que fornecerá subsídios para uma melhor compreensão da atual e conturbada guerra civil, iniciada em 2011. Em suas palavras: "People may know what's going on in Syria today, but how did Syria get to where it is today, at the forefront of The Arabic Sprig?" (p. 2).

Apesar de Hall escrever para um público acadêmico e leigo, o que vemos nos 73 capítulos distribuídos em 34 partes é um inventário de fatos e datas. A narrativa é iniciada com a ascensão e queda do Império Otomano e se conclui relatando os atuais conflitos internos no país.

Segundo o autor, no último século, a história síria foi marcada pela violência, e uma das causas disso se encontra no sectarismo religioso que interfere nas relaçóes sociais e políticas do país: "Within that narrative are a number of sensitive issues, including sectarian strife between the majority Sunni population and the Alawites, not to mention Christians" (p. 2). A contextualização sugerida, assim como o mapeamento e a descrição dos fatos que antecederam o conflito são fundamentais para que o leitor possa avaliar melhor os caminhos da guerra. Hall acredita que seu texto seja capaz de indicar e analisar as diversas variantes políticas do país, já que estas afetam toda a região: “(...) was a toxic and twisted mess that has precipitoulsy affected the entire region, from Israel and Lebanon to Iran and Iraq" (p. 2).

O primeiro capítulo, "The Ottoman Empire", faz uma brevíssima apresentação acerca das origens do mesmo até sua derrocada. Todos os demais capítulos iniciais da primeira parte, "Before nationhood", dedicam-se a descrever a administração do governo otomano na região e a fornecer datas que culminariam com a sua queda, no final da Grande Guerra.

Em "Dividing the spoils after the Ottoman collapse", segunda parte do livro, é feita uma comparação crítica da divisão do referido Império com a que foi realizada pelas potências ocidentais após a queda de Saddam Hussein, no Iraque, em 2003. De acordo com o autor: " $A$ major criticism of the invasion of Iraq and overthrow of Saddam Hussein was the apparent absence of planning for what would follow, specifically how Iraq was to be governed. 85 years earlier, the Great Powers were severely criticized for their plans to divide the Ottoman spoils of war" (p. 7). 
Ainda nesta parte, faz um mapeamento dos acordos que dividiram o Império Otomano a partir de 1861 e, finalmente, na terceira parte, começa um relato da história síria no século XX, que se mistura à narrativa de todos os povos do mundo árabe.

Hall destaca, como parte da história do país, o Protocolo de Damasco. Esse documento, datado de 1914, declarava o apoio de vários grupos árabes a Faisal Hussein Bin Hussein contra o Império Otomano e definia a criação de um Estado Árabe independente. Se na introdução do livro o autor afirmava que apresentaria mapas, "Along with maps showing how the modern state of Syria came to be formed (...)" (p. 2), já no capítulo "1914: Damascus Protocol", deixou de fazê-lo, embora a apresentação desse mapa fosse importante para que se pudesse melhor compreender o espaço geográfico que o Estado Árabe preconizado pelo Protocolo ocuparia.

Em todos os demais acordos listados por Hall e que nomeiam os capítulos, vê-se, apenas, uma breve descrição dos fatos e dos personagens do Ocidente envolvidos; nesse aspecto, o livro atinge seu objetivo para um público leigo, mas não para o acadêmico, pois deixa de citar nomes como o do coronel T. E. Lawrence, o lendário Lawrence da Arábia, figura importante na articulação da Revolta Árabe de 1916-1918 contra os otomanos, ou ainda o de Muhamad Sharif Al Faruqi, um dos mais importantes membros das sociedades secretas árabes. Sharif teve papel importante no Protocolo de Damasco assim como, mais tarde, na formaçấo do nacionalismo árabe.
No capítulo "And the French came", explicitam-se a queda do rei Faysal, em 1920, a consequente derrota das tropas sírias e a divisão do país pelos mandatários em seis entidades territoriais de acordo com a confissão religiosa. $\mathrm{O}$ início do Mandato Francês na Grande Síria (atuais Síria, Líbano, Palestina e Jordânia) é narrado por Hall como a grande vitória europeia na região. Em suas palavras: "France was determined to assert what they saw as their rights in Lebanon and Syria, based on history (...)" (p. 13), mas o autor passa ao largo dos levantes contra os franceses durante o período, como também da utilizaçấo da ideia de Grande Síria pelos nacionalistas para justificar a criaçâo de um grande Estado Árabe.

O autor recorreu aos 112 anos da história síria para reforçar uma visáo eurocêntrica de um país do conturbado Oriente Médio, preocupando-se em listar os acontecimentos e construir um discurso em que a dominação europeia tinha "uma missão civilizatória e apaziguadora". Tal posicionamento de Hall ilustra-se não apenas na já observada omissão de nomes de personagens árabes como também na descrição da reação dos sírios ao Mandato Francês: "However, nearly all the Syrian sects were hostil to the French Mandate and to the division it created" (p.17), ou, ainda, quando se refere ao período pós-independência do país, no capítulo "French bomb Damascus", afirmando que foram tempos de muita instabilidade no local, mas não oferecendo nenhuma justificativa para sua afirmativa. Nesse período (1946), a Síria foi palco de diferentes sublevaçôes, portanto, para um livro que se propóe a analisar 
os fatos históricos, a informação fica incompleta. O capítulo se encerra com a frase "The early years of independence were marked by political instability" (p. 26). O que poderia ser uma sentença de efeito para introduzir um próximo capítulo adquire um caráter conclusivo, mas insuficiente, pois somente o seguinte, "1947: United Nations partition plan for Palestine”, apresentará detalhes acerca da resolução da ONU sobre a criação do Estado de Israel e a reação negativa da Liga Árabe. Assim, na visão ocidental, a Síria é vista como motivadora dos ataques contra Israel - "Armed bands of irregulars from Syria's fledgling armed forces began to raid Jewish settlements near the Syrian border" (p. 28).

Dessa forma, desde o ponto de partida do livro, "Before nationhood", há indícios de que as diversas expressóes do nacionalismo sírio, mais adiante, seriam discutidas com a profundidade por um estudioso do assunto, o que não acontece. Fatos sobre a formação desse nacionalismo são apresentados, mas distantes de questôes levantadas pelo Partido Socialista Nacionalista Sírio ou pelo Partido Socialista Ba’ath (que está no poder há quarenta anos), e tampouco se apontam as interseçôes nem as diferenças entre eles.

No capítulo "Arabs losses", o autor dedica-se em apresentar o número de árabes mortos na guerra contra Israel e o de palestinos expulsos de suas casas. Aqui apenas são listadas as perdas árabes no conflito contra Israel; já no capítulo "Military Cops of 1949 and colonel Adib Shishakli", Hall detalha a ascensão e derrocada de vários presidentes num espaço de um ano. Embora assuma que o presidente Hosni Za'im tenha chegado ao poder mediante um golpe de Estado promovido pelos EUA, governando por apenas cinco meses, o autor não informa ao seu leitor que, em seu brevíssimo governo, Za’im aumentou os impostos, prendeu nacionalistas sírios, executou Antoun Sa’ade, presidente do Partido Socialista Nacionalista Sírio, com a ajuda do israelense Ben Gurion, e fez um acordo de paz com Israel, recebendo em torno de 300 mil refugiados palestinos na Síria; por conseguinte, setores militares insatisfeitos o depuseram. Essa foi a primeira consequência da Catástrofe da Palestina (a Nakba - a catástrofe que se abateu sobre o povo palestino e os demais países árabes em decorrência da criação do Estado de Israel em 1948) na regiáo. O conhecimento desse fato ajudaria a compreender o porquê do discurso de apoio aos palestinos ser a bandeira dos nacionalistas e poderia explicar o alinhamento da Síria à URSS durante a Guerra Fria, por exemplo.

Em "Alawite State", capítulo dedicado aos alauítas, grupo muçulmano ao qual pertence a família do atual presidente Assad, o autor dedica um espaço maior, explicando sua origem religiosa. No entanto, traz informaçôes discutíveis e equivocadas sobre eles, por exemplo, ao afirmar que "Their practices are considered unusual, as they do not follow the rules on prayer, fasting and wine, and a doctrine called taqiya permits them to make false declarations about their beliefs should the circunstances demand it to avoid persecution" (p. 18). Certamente, Hall se baseou numa bibliografia muito usada por europeus do início do século passado, que partiam de registros apresentados por outros grupos 
muçulmanos, já que os alauítas, ainda hoje, pouco divulgam suas açôes de caráter esotérico e são poucos os estudiosos que conseguem ter acesso a algumas dessas práticas.

Se, por um lado, o Mandato Francês foi violento na repressão, por outro, na visão eurocêntrica, foi salvador para os alauítas, pois lhes garantia a liberdade de culto. Nas palavras do autor: "One of the terms of the mandate was that all persons in the territory given under French control should be allowed to follow their own religious practice (...)" (p. 18). A possibilidade de poderem praticar seus ritos sem serem repreendidos seduziu os alauítas, que passaram a ver os franceses com mais simpatia. Embora o sentimento de construir a Grande Nação Síria estivesse sedimentado em sua cultura, a estabilidade religiosa sobrepunha-se ao nacionalismo. Apresenta-se, assim, a motivação que aproximou os alauítas dos franceses, mas não se explicita a que aproximou os franceses dos alauítas, nem o porquê da criação do Estado, em "1924" (envolvendo as montanhas da costa do Mediterrâneo, as cidades de Latakia e Tartus, curiosamente poupadas pela atual guerra civil, e o norte do Líbano - Trípoli e Akkar), só para eles. Uma barganha que envolvia ambas as partes foi feita; por um lado, os alauítas apoiariam os franceses para a expulsão dos otomanos da regiáo e, por outro, ganhariam um Estado só para eles, o que os livraria das perseguiçóes religiosas e lhes daria uma estabilidade econômica, já que viviam em extrema pobreza. Entretanto, a administração política e econômica, obviamente, seria feita pelos franceses. A liberdade de expressão prometida pelos franceses foi uma estratégia, não apenas para angariar apoio e força, mas, principalmente, sob esse pretexto, aplicou-se o método imperial utilizado em outras colônias: dividir para melhor dominar.

No tocante a esse tema, Hall comete alguns equívocos, pois, além de se basear em fontes ideologicamente comprometidas contra os alauítas, erra na data da criaçáo do seu Estado, que foi 1920, e náo 1924, como o autor afirma. Em 1920, houve a delimitação do espaço da comunidade, entre 1921 e 1924, as fronteiras foram retificadas pelos mandatários, incluindo, então, os cantôes de Baer, Bassi e Akkrad, de populaçáo sunita. De 1924 a 1936 o Estado sobreviveu, nunca com a tranquilidade esperada, já que a anexaçáo dos cantóes de maioria sunita aumentava a instabilidade na regiáo. Novamente algumas omissóes de personagens, como as lideranças do nacionalista Zaki Al 'Arsuzy, ou ainda de seguidores de Saleh Al Ali, chefe religioso dos alauítas e nacionalista sírio, que liderou os Levantes de 1919 e 1921, e, mesmo exilado, mantinha sua influência no grupo, pois era inimigo declarado dos mandatários, por perceber que a criação de um Estado Alauíta não mudaria as relaçóes de dominação da França. Os franceses integraram todas as regióes sob um único governo, em 1936, em nome de seu domínio e pressionados pela elite sunita, visto que também temiam mais um Levante Druzo (grupo religioso que se inscreve no islã).

A visão imperialista de Clement Hall, que serviu à Força Aérea Britânica na regiáo, não aponta o uso da força militar na Grande Síria, durante o Mandato Francês. Os fatos 
se referem às reaçôes contra os mandatários como pequenos levantes e às soluçôes encontradas em gabinetes franceses ou por meio de conchavos com as lideranças locais.

Algumas perguntas sobre a chegada do partido Ba'ath ao poder, o nascimento do partido na Síria, os primeiros anos deste na presidência, o golpe dado pelos militares liderados por Hafez al-Assad e a relação que há entre a atual perseguição aos alauítas e açôes do governo Bashar desde a sua posse não são respondidas, fornecendo-se ao leitor apenas as datas dos eventos.

Em 1982, acontece um dos maiores massacres contra a população civil na Síria. A Irmandade Muçulmana, grupo ativista político sunita que luta pela implantaçáo das Leis Islâmicas (shari'a) nos países árabes e muçulmanos, organizava-se, no país, desde 1976. A ascensão do Partido Ba'ath ao poder, que implantava um Estado laico, a chegada de Hafez Al-Assad à presidência, um alauíta, grupo historicamente adverso aos sunitas, o exército sob comando de alauítas, em especial, e o desejo de unificar os países sob a bandeira do Islá, levaram esses sunitas a um processo de luta pela derrubada de Assad e do seu Partido. Um período de terror se instaura no país, com perseguiçóes, prisôes, torturas e mortes de membros da Irmandade Muçulmana, que teve sua culminância com o Massacre de Hamas, em 1982. Tropas do exército sírio eliminaram entre 10 mil e 40 mil pessoas, na cidade de Hamas, bem como muitas foram presos. Ao mesmo tempo que a opressão às manifestaçốes contrárias ao regime é narrada, Hall explica, encerrando o capítulo, entre parênteses, como se fosse uma informação não essencial, que Assad libertou alguns nos anos 1990: "During the rest of Hafez al-Assad's reign, there were only a few public manifestations of anti-regime activity. (Having suppressed all opposition, Hafez al-Assad released some imprisoned members of the Brotherhood in the mid-1990s)" (p. 48).

De todas as rebeliōes que o governo de Assad, pai, sofreu, desde sua ascensão, Hall dedica dois longos capítulos, "Muslim brotherhood and Hama" e "Muslim brotherhood", às promovidas pela Irmandade Muçulmana. Chama a atenção o silêncio absoluto do autor em relação às prisóes e aos massacres de comunistas promovidas pelo governo de Hafez Al-Assad. Entretanto, não é de se estranhar, essa atitude pode ser justificada, pois Hall é um ex-membro do serviço secreto das forças aéreas britânicas.

Um dos pontos mais sensíveis da história recente da Síria é a Guerra Civil Libanesa (1975-1990). O regime político do Líbano é regido pelo confessionalismo, em que cada comunidade religiosa se transformou num órgão político, incompatibilizando, assim, os interesses do Estado Libanês. O capítulo que trata sobre a guerra libanesa, "Intervention in Lebanon", é mais um relato de datas, lembrando um diário de bordo, sem justificar a participação da Síria na referida Guerra e sua posterior retirada, nem aprofundar as relaçóes da Síria com o Líbano no "pré" e no pós-guerra.

Em 2000, com a morte do presidente Hafez al-Assad, ao contrário do que ocorre no presidencialismo democrático do Ocidente, não foi o vice-presidente Abdul Hamid Khadem quem assumiu, e sim o filho 
de Hafez. Após uma manobra política do partido Ba'ath para pôr fim a uma exigência constitucional que limitava a idade mínima de quarenta anos, Bashar é referendado como presidente da República aos 34 anos, pelo Parlamento, em julho de 2000.

Novamente, a ascensão de Bashar ao poder é contemplada por Hall apenas com a apresentaçáo de algumas datas e ações que marcaram sua política inicial. Lembra que o presidente sírio, assim que assumiu, libertou seiscentos presos políticos, entre eles, islamitas da Irmandade Muçulmana, mas deixa o leitor sem resposta diante da questâo sobre a motivação que o líder sírio teve para promover tais reformas, qual é o interesse do Ocidente por elas e que relação tem o não cumprimento das propostas de abertura política com o inicial apoio americano e europeu às rebeliôes de 2011. Reconhece os fracassos das tímidas tentativas de mudanças apresentadas pelo atual presidente, mas não discute por que tal regime não foi capaz nem de democratizar e muito menos de reformar o Estado.

Passados três anos de guerra civil, a despeito de todas as expectativas ocidentais, Bashar Al-Assad continua no poder, ao contrário dos presidentes Saddam Hussein (Iraque), Hosni Mubarak (Egito) e Muammar Kadafi (Líbia). Na parte final do livro, "The situation in Syria", embora o autor reconheça que o presidente continue a governar, deixa em suspenso para o leitor o que motivou o apoio de outros países da região ao conflito local e como Bashar ainda se mantém na presidência, com aval popular. Hall fornece apenas o número de mortos e refugiados e informa sobre a posiçáo das grandes potências do Ocidente. Em nenhuma passagem do livro o autor estabelece relações entre os fatos formadores da história da Síria desde 1900 e a situação atual ou faz uma avaliação mais aprofundada da conjuntura, o que seria extremamente esclarecedor em um ano eleitoral.

Sabendo-se que Clement Hall serviu à Força Aérea Britânica, esperava-se que uma análise sob o ponto de vista das estratégias militares fosse adotada e assim, pelo menos, seria possível compreender a história do país a partir de uma perspectiva militar. Mas a arabofobia de Hall o impediu de refletir tanto sobre a história política e social quanto sobre o aspecto militar. A lacuna sobre a história da Síria contemporânea continua em aberto.

\footnotetext{
* Doutora em teoria e história literária pela Universidade Estadual de Campinas, pesquisadora do Grupo de Pesquisa Leitura e Fruição da Universidade Federal Fluminense, Niterói, RJ, Brasil. E-mail: m_omran@uol.com.br.
} 